\title{
Biocompatibility of phosphorylcholine coated stents in normal porcine coronary arteries
}

\author{
D M Whelan, W J van der Giessen, S C Krabbendam, E A van Vliet, P D Verdouw, \\ $P$ W Serruys, $H$ M $M$ van Beusekom
}

\begin{abstract}
Objective-To improve the biocompatibility of stents using a phosphorylcholine coated stent as a form of biomimicry.

Interventions-Implantation of phosphorylcholine coated $(n=20)$ and non-coated $(n=21)$ stents was performed in the coronary arteries of 25 pigs. The animals were killed after five days $(n=6)$, four weeks $(n=7)$, and 12 weeks $(n=8)$, and the vessels harvested for histology, scanning electron microscopy, and morphometry.

Main outcome measures-Stent performance was assessed by studying early endothelialisation, neointima formation, and vessel wall reaction to the synthetic coating.

Results-Stent thrombosis did not occur in either group. Morphometry showed no significant differences between the two study groups at any time point. At five days both the coated and non-coated stents were equally well endothelialised ( $91 \% v 92 \%$, respectively). At four and 12 weeks there was no difference in intimal thickness between the coated and non-coated stents. Up to 12 weeks postimplant the phosphorylcholine coating was still discernible in the stent strut voids, and did not appear to elicit an adverse inflammatory response.

Conclusion-In this animal model the phosphorylcholine coating showed excellent blood and tissue compatibility, unlike a number of other polymers tested in a similar setting. Given that the coating was present up to 12 weeks postimplant with no adverse tissue reaction, it may be a potential candidate polymer for local drug delivery.

(Heart 2000;83:338-345)
\end{abstract}

Keywords: phosphorylcholine; stents; coatings; biocompatible materials

Significant advances have been made in the field of interventional cardiology through the use of coronary stents. A restenosis rate of $30-50 \%$ after balloon angioplasty has been reduced to a current rate of $10-30 \%$ after stenting. Such a reduction has led to the use of stents in wider patient populations with improved clinical outcome. In addition, improvements in implantation techniques together with enhanced antiplatelet regimens have greatly reduced acute ischaemic events ${ }^{1}$ $\left(<2 \%\right.$ when stents are implanted electively ${ }^{2}$ and approximately $5 \%$ in bailout situations ${ }^{3}$ ). Both antirestenosis and antithrombotic aspects must be addressed, however, if the stent's therapeutic potential is to be expanded even further. Such improvements may be achieved by enhancing the biocompatibility of the implant.

Modification of a stent with respect to blood and tissue compatibility can be achieved by changing the stent material itself, or by modifying the outer layer of the stent surface. Changing the stent material may influence the

Accepted 19 October 1999

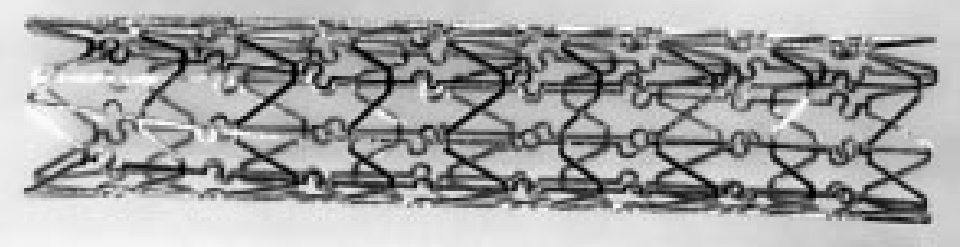

Figure 1 A macroscopic view of the divYsio stent. mechanical behaviour of the stent, but since only the outer few micrometres of the metal interact with the blood and tissue wall, it is more practical to modify the outer stent surface by coating it with a biocompatible molecule. The ideal coating would be haemocompatible, thereby not inducing stent thrombosis, and could potentially reduce neointimal thickening through improved tissue compatibility.

Previous studies have highlighted the success of phosphorylcholine in improving the biocompatibility of surfaces. ${ }^{4-7}$ In our study the phosphorylcholine coating applied to a metallic coronary stent (fig 1) consists of a copolymer of laurylmethacrylate and methacryloylphosphorylcholine, the latter as the phosphorylcholine component. ${ }^{8}$ The zwitterionic head group of phosphorylcholine provides a hydrophilic surface while retaining an overall neutral charge (fig 2). The phosphorylcholine head group that is held responsible for improving biocompatibility accounts for a small part of the coating, while the majority of the coating consists of components to give the required adhesion to the metal surface. Although the phosphorylcholine component is based on a naturally occurring phosphatidylcholine (a constituent of the lipid bilayer of the cell membrane), the current coating must be regarded as entirely synthetic. As many synthetic polymers have been associated with aggressive inflammatory reactions and excessive neointimal growth, ${ }^{9}$ it is important to study both the early and late response to the coating. 


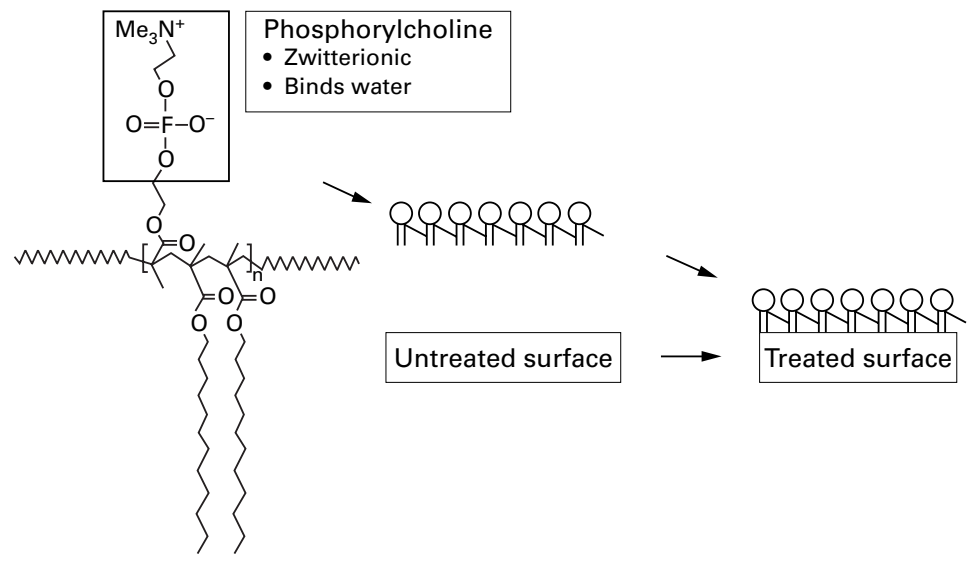

Figure 2 Schematic representation of the phosphorylcholine coating applied to the divYsio stent (modified from Campbell and colleagues').

Our study therefore aimed to assess the blood and tissue biocompatibility of the phosphorylcholine coating, particularly its influence on the wound healing response, its effect on subsequent neointima formation, and the vessel wall reaction to the synthetic coating, in a porcine coronary stent model.

\section{Methods}

BALLOON EXPANDABLE STENT

The stent used in the current study is the balloon expandable div Ysio stent (Biocompatibles Cardiovascular, Farnham, UK) (fig 1). This stent, which is $15 \mathrm{~mm}$ long, has an interlocking arrowhead design and is constructed of medical grade stainless steel $316 \mathrm{~L}$. Both phosphorylcholine coated and non-coated (bare) stents were used in the study.

PHOSPHORYLCHOLINE COATING

The coating applied to the divYsio stent consists of a copolymer of methacryloylphosphorylcholine and laurylmethacrylate. The stents were dip coated from a solution of the polymer in ethanol to give a coating that is approximately $50 \mathrm{~nm}$ thick. The stents were received precoated and sterilised from the manufacturer.

\section{ANIMAL CARE AND PREPARATION}

Experiments were performed under the regulations of the animal care committee of the Erasmus University Rotterdam and in accordance with standard guidelines.

Experiments were performed in crossbred Landrace Yorkshire pigs $(30 \mathrm{~kg})$ as previously described. ${ }^{10}$ Starting one day before the procedure and throughout the follow up period, all animals received $300 \mathrm{mg}$ carbasalatum calcium (Ascal; Asta Medica BV, The Netherlands) by mouth daily. After an overnight fast the animals were sedated with $20 \mathrm{mg} / \mathrm{kg}$ ketamine hydrochloride. Anaesthesia was induced by $11 \mathrm{mg} / \mathrm{kg}$ thiopental and, following endotracheal intubation, the pigs were connected to a ventilator that administered a mixture of oxygen and nitrous oxide (1:2, vol/vol). Anaesthesia was maintained with 1-2.5 vol \% isoflurane. Antibiotic prophylaxis was administered by an intramuscular injection of a preparation containing $200 \mathrm{mg}$ procaine benzylpenicillin and
Table 1 Distribution of stents in coronary vessel pairs at different time points

\begin{tabular}{llll}
\hline Vessel pairs & 5 days & 4 weeks & 12 weeks \\
\hline LAD/LCX & 5 & 4 & 5 \\
LAD/RCA & 1 & 0 & 0 \\
LCX/RCA & 0 & 1 & 0 \\
LAD only & 0 & 3 & 4 \\
LCX only & 0 & 0 & 2 \\
\hline
\end{tabular}

Table 2 Distribution of coated and non-coated stents in coronary arteries at different time points

\begin{tabular}{llll}
\hline & $L A D$ & $L C X$ & $R C A$ \\
\hline 5 days & & 2 & 0 \\
$\quad$ Coated & 4 & 2 & 1 \\
$\quad$ Non-coated & 3 & 1 & 0 \\
4 weeks & 5 & 4 & 1 \\
$\quad$ Coated & 2 & 3 & 0 \\
$\quad$ Non-coated & 5 & 4 & 0 \\
$\quad$ weeks & 4 & & \\
$\quad$ Coated & & & \\
$\quad$ Non-coated & & & \\
\hline
\end{tabular}

$250 \mathrm{mg}$ dihydrostreptomycin sulfate per $\mathrm{ml}$ (Streptoprocpen; AUV, Cuijk, The Netherlands) at a dose of $1 \mathrm{ml}$ per $25 \mathrm{~kg}$ bodyweight as a standard laboratory procedure. Under sterile conditions an arteriotomy of the left carotid artery was performed and an $8 \mathrm{~F}$ introduction sheath was placed. After measurement of arterial blood pressure and heart rate, and withdrawal of an arterial blood sample for the measurement of activated partial thromboplastin time (APTT), blood gases, and acid base balance (settings of the ventilator corrected, if necessary), $10000 \mathrm{IU}$ heparin sodium and $250 \mathrm{mg}$ aspirin were administered through the sheath and an $8 \mathrm{~F}$ guiding catheter was advanced to the ascending aorta. An APTT of at least three times baseline was maintained throughout the procedure. Coronary angiography was performed using a contrast agent (Omnipaque; Nycomed Ireland Ltd, Cork, Ireland), and quantitative angiographic analysis was performed using the edge detection method (Cardiovascular Measurement System; Medis Inc, Nuenen, The Netherlands). ${ }^{11}$

STENT IMPLANTATION

From the angiograms, a coronary segment with a diameter of $2.5-3.5 \mathrm{~mm}$ was selected in the proximal left anterior descending coronary artery (LAD), left circumflex coronary artery (LCX), or right coronary artery (RCA), using online quantitative coronary angiography. Stents were randomised and implanted in a paired fashion in separate coronary arteries. While a preference was given for the LAD/ LCX (14 animals), stents were also implanted in the LAD/RCA (one animal) and LCX/RCA (one animal). Because of vessel size or tapering in the remaining nine animals, stents were implanted in single vessels (tables 1 and 2). Side branches and curved coronary artery segments were not avoided. A phosphorylcholine coated or non-coated stent was crimped onto a deflated balloon and advanced over a 0.014 inch steerable guidewire to the preselected site for implantation. The balloon was then inflated for 30 seconds (mean inflation pressure 9 atm), deflated, and negative pressure maintained for 60 seconds. Matched 
Table 3 Quantitative coronary angiography (QCA) at five days, four weeks, and 12 weeks, after implantation of the phosphorylcholine coated and non-coated stents

\begin{tabular}{llllll}
\hline & $\begin{array}{l}Q C A \text { pre } \\
(\mathrm{mm})\end{array}$ & $\begin{array}{l}\text { QCA post } \\
(\mathrm{mm})\end{array}$ & $\underset{(\mathrm{mm})}{Q C A \text { follow up }}$ & B:A ratio & $n$ \\
\hline 5 days & $2.9(0.5)$ & $3.1(0.3)$ & $3.0(0.3)$ & $1.1(0.1)$ & 6 \\
$\quad$ Coated & $3.2(0.3)$ & $3.3(0.3)$ & $3.2(0.3)$ & $1.0(0.0)$ & 6 \\
$\quad \begin{array}{l}\text { Non-coated } \\
\text { weeks }\end{array}$ & & & & \\
$\quad$ Coated & $3.2(0.2)$ & $3.3(0.2)$ & $2.8(0.5)$ & $1.0(0.1)$ & 7 \\
$\quad$ Non-coated & $2.9(0.4)$ & $3.1(0.2)$ & $3.0(0.3)$ & $1.2(0.2)$ & 6 \\
$\begin{array}{l}12 \text { weeks } \\
\quad \text { Coated }\end{array}$ & $3.0(0.3)$ & $3.1(0.5)$ & $3.2(0.5)$ & $1.0(0.1)$ & 8 \\
$\quad$ Non-coated & $3.0(0.3)$ & $3.0(0.3)$ & $2.9(0.4)$ & $1.0(0.1)$ & 8 \\
\hline
\end{tabular}

Data presented as mean (SD); B:A ratio, balloon:artery ratio; n, number of stented coronary arteries.

implantation of the stent and artery was performed, such that the intended balloon:artery ratio was as near to 1 as possible. The catheter was then slowly withdrawn while leaving the stent in place. After repeat angiography, the guiding catheter and the introducer sheath were removed, the arteriotomy repaired, and the skin closed in two layers. At the end of the procedure, the animals were allowed to recover and returned to the animal care facilities.

In total, 41 stents ( 20 coated, 21 non-coated) were implanted into 25 animals; these animals were assigned to three groups (tables 1 and 2) to study the progress of wound healing and neointima formation at five days, four weeks, and 12 weeks.

FOLLOW UP ANGIOGRAPHY

The anaesthesia and catheterisation procedures at follow up were similar to those described above, while coronary angiography was performed in the same projection, and using identical settings of the radiographic equipment, as during implantation.

MICROSCOPICAL EXAMINATION

After angiography at follow up, the thorax was opened by a midsternal split and a lethal dose of sodium pentobarbital was injected intravenously, immediately followed by cross clamping of the ascending aorta. After puncturing the aortic root above the coronary ostia, $300 \mathrm{ml}$ of saline was infused under a pressure of $150 \mathrm{~cm} \mathrm{H} \mathrm{H}_{2} \mathrm{O}$, followed by $500 \mathrm{ml}$ of $2.5 \%$ glutaraldehyde in $0.15 \mathrm{~mol} / 1$ cacodylatebuffer for scanning electron microscopy (SEM) or $500 \mathrm{ml}$ of $4 \%$ buffered formaldehyde for light microscopy. The heart was then excised and the coronary arteries dissected free from the epicardial surface. The stented and adjacent unstented $(5 \mathrm{~mm})$ segments were kept in fixative for at least 24 hours and thereafter were further processed for light microscopy ${ }^{12}$ or for
SEM as previously described..$^{10}$ For light microscopy, stented vessels were embedded intact in methylmethacrylate, sectioned, and stained with haematoxylin and eosin as a routine stain, and resorcin-fuchsin as an elastin stain. Lectin histochemistry was performed to confirm the identity of the regenerated endothelium. ${ }^{13}$

\section{MORPHOMETRY}

Morphometric analysis of the neointimal formation in vessels processed for light microscopy was performed in the proximal, middle, and distal stent segment on elastin stained sections by tracing the external and internal elastic laminae and the endothelial lining using a microscopy image analysis system (Impak C, Clemex vision Image analysis system; Clemex Technologies, Quebec, Canada). The media was defined as the layer between the internal and external elastic laminae. The area between the endothelial lining and the internal elastic lamina was taken as the intima.

SCANNING ELECTRON MICROSCOPY AND PLANIMETRY

SEM was performed to study endothelial regrowth at five days. After fixation with $2.5 \%$ glutaraldehyde in $0.15 \mathrm{~mol} / 1$ cacodylate buffer, the arteries were further processed as previously described. ${ }^{10}$ Assessment of endothelial regrowth was performed by studying eight areas in the proximal, middle, and distal stent segments of vessels by SEM. From photographs of these areas, the stent struts were traced, the endothelium marked, and the percentage endothelial coverage of the stent struts quantified using computer assisted planimetry.

STATISTICAL ANALYSIS

Data were analysed using Jandel Sigmastat statistical software, version 2.0 (Jandel Corporation). All data are expressed as mean (SD) or as median (range). The angiographic and morphometric data were evaluated by a two way repeated measures analysis of variance (ANOVA) and a two way ANOVA, respectively, followed by a Student-Neuman Keuls test. A value of $\mathrm{p}<0.05$ was considered significant.

\section{Results}

PROCEDURAL SUCCESS

A total of 20 phosphorylcholine coated and 21 non-coated stents (25 animals) were implanted successfully. All animals survived the follow up period without stent thrombosis or other adverse events. In the four week group,

Table 4 Morphometric analysis at four and 12 weeks after implantation of the coated and non-coated stents

\begin{tabular}{|c|c|c|c|c|c|c|c|}
\hline & $\begin{array}{l}\text { Lumen area } \\
\left(m m^{2}\right)\end{array}$ & $\begin{array}{l}\text { Neointimal area } \\
\left(\mathrm{mm}^{2}\right)\end{array}$ & $\begin{array}{l}\text { Media area } \\
\left(\mathrm{mm}^{2}\right)\end{array}$ & $\begin{array}{l}\text { Neointimal thickness } \\
\text { at stent struts }{ }^{\star}(\mathrm{mm})\end{array}$ & $\begin{array}{l}\text { Media thickness at } \\
\text { stent struts (mm) }\end{array}$ & $\begin{array}{l}\text { Neointimal thickness } \\
\text { between stent struts ( }(\mathrm{mm})\end{array}$ & $\begin{array}{l}\text { Media thickness between } \\
\text { stent struts }(\mathrm{mm})\end{array}$ \\
\hline \multicolumn{8}{|l|}{4 weeks } \\
\hline Coated $(\mathrm{n}=7)$ & $5.76(1.63)$ & $1.71(0.67)$ & $1.46(0.55)$ & $0.24(0.09)$ & $0.09(0.04)$ & $0.18(0.08)$ & $0.13(0.03)$ \\
\hline Non-coated $(n=6)$ & $6.82(2.27)$ & $1.81(0.99)$ & $1.24(0.11)$ & $0.25(0.13)$ & $0.08(0.02)$ & $0.18(0.13)$ & $0.13(0.02)$ \\
\hline \multicolumn{8}{|l|}{12 weeks } \\
\hline $\begin{array}{l}\text { Coated }(\mathrm{n}=8) \\
\mathrm{n}=6\end{array}$ & $5.89(1.37)$ & $\begin{array}{l}2.22(1.54) \\
1.38(0.54) \dagger\end{array}$ & $1.18(0.29)$ & $\begin{array}{l}0.32(0.22) \\
0.20(0.08) \dagger\end{array}$ & $0.06(0.02)$ & $\begin{array}{l}0.23(0.18) \\
0.14(0.07) \dagger\end{array}$ & $0.12(0.04)$ \\
\hline $\begin{array}{l}\text { Non-coated }(\mathrm{n}=8) \\
\mathrm{n}=7\end{array}$ & $6.16(1.79)$ & $\begin{array}{l}1.41(0.77) \\
1.19(0.48) \dagger\end{array}$ & $1.13(0.15)$ & $\begin{array}{l}0.22(0.12) \\
0.19(0.07) \dagger\end{array}$ & $0.06(0.01)$ & $\begin{array}{l}0.15(0.11) \\
0.12(0.06) \dagger\end{array}$ & $0.12(0.02)$ \\
\hline
\end{tabular}

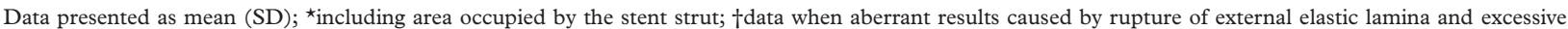
inflammatory reaction have been excluded. 

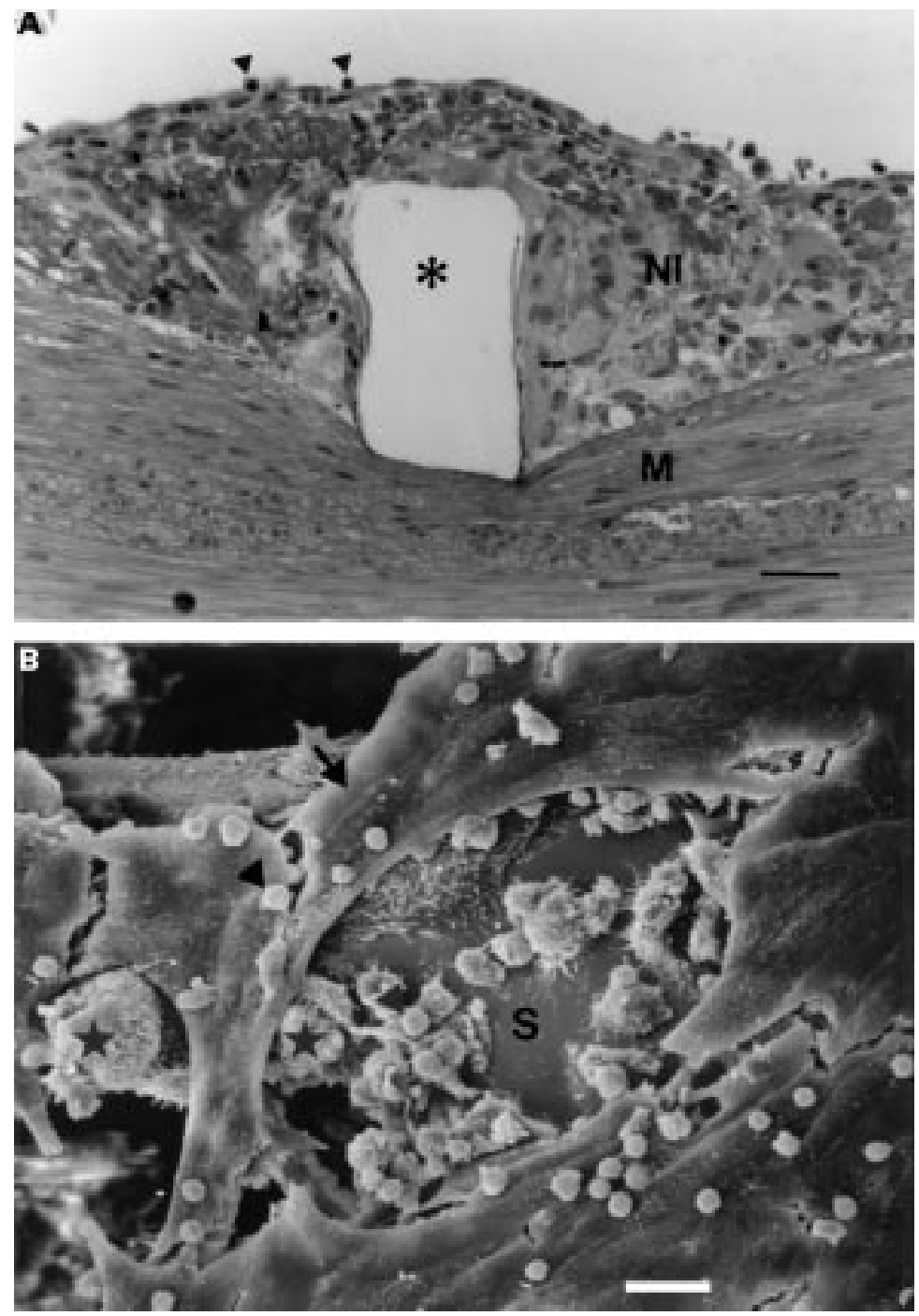

Figure 3 (A) Light microscopy of the intimal thickening at five days postimplant, showing granulation tissue over the stent wire void $\left({ }^{\star}\right)$, with occasional leucocytes (arrowheads) attached to the endothelium (bar = $30 \mu \mathrm{m})$. NI, neointima; $M$, media; haematoxylin and eosin. (B) SEM of a stent strut (S) at five days, showing an incomplete endothelial lining (arrow), with leucocytes (arrowheads) and macrophages ( ${ }^{\star}$ ) occupying areas devoid of endothelium (bar $=20 \mu \mathrm{m}$ ).

however, there was one incidence of stent collapse, where the excised stented vessel appeared to be elliptical rather than round.

QUANTITATIVE ANGIOGRAPHIC MEASUREMENTS

Quantitative angiographic measurements are summarised in table 3 . With a mean balloon diameter of $3.1(0.3) \mathrm{mm}$ at maximal pressure, stent recoil was $2(7) \%$. The results at five days, four weeks, and 12 weeks showed no significant difference in late loss (post versus follow up) between the coated and non-coated groups. There appeared to be a trend, however, towards an increased late loss in the coated group at four weeks which is explained by one incidence of stent collapse in this group (angiographic late loss then seems abnormally large). Such a trend was not observed in the morphometric results and therefore deemed unimportant. Indeed, the neointimal thickness in this group was identical to that of the control group at four weeks (table 4).
GENERAL HISTOPATHOLOGY AND PERFORMANCE OF THE STENT COATING

Histopathology at five days

In this group, two vessels (one animal: one coated, one non-coated) were examined by light microscopy and the remainder by SEM for evaluation of endothelialisation. In the two arteries examined by light microscopy the intimal thickening consisted of organising thrombus or granulation tissue containing inflammatory cells (macrophages, macrophage giant cells, granulocytes) (fig 3A). In both vessels, macrophage giant cells were frequently seen surrounding the stent struts voids. In the coated group, the purple stained coating was still discernible in the stent strut voids and did not appear to elicit an adverse inflammatory response. Both arteries showed adhesion and infiltration of leucocytes to an incomplete endothelial layer, the identity of the endothelium being confirmed by lectin histochemistry. The medial and adventitial layers were normal. In both the coated and non-coated groups SEM showed an advanced but incomplete endothelial covering, with macrophages frequently occupying the areas that were devoid of endothelium (fig 3B).

Histopathology at four weeks

At four weeks in both the coated and non-coated groups, the asymmetric neointima (fig 4) consisted of smooth muscle cells in an extracellular matrix, covered by an endothelial layer with some adherent leucocytes. Towards the intimal/medial border zone the cellular density was distinctly less and the cells were in a haphazard orientation with some containing thrombus remnants, inflammatory cells, and foam cells. Macrophage giant cells were observed surrounding the stent strut voids in both groups. In areas of maximal intimal thickening there was often abundant extracellular matrix. The medial and adventitial layers were only affected by inflammation in the case of medial ruptures or complete dissection (four vessels: two coated, two non-coated), but these inflammatory changes were discrete. In the coated group, the purple stained coating in the stent strut voids was discernible in five of the seven vessels.

\section{Histopathology at 12 weeks}

In both groups the neointima consisted of smooth muscle cells in an extracellular matrix with an organisation similar to that observed in the four week group, except that the intimal/ medial border zone sometimes contained acellular areas. In this border zone, inflammation and neovascularisation were observed concomitant with medial damage. Some diffuse inflammatory infiltrates were seen in the adventitia (three vessels). In the coated stented arteries purple stained coating was still observed in the stent strut voids in six out of eight vessels (fig $5 \mathrm{~A}$ ).

\section{MORPHOMETRY}

Endothelialisation

At five days the percentage of endothelium covering the stent struts was determined using 


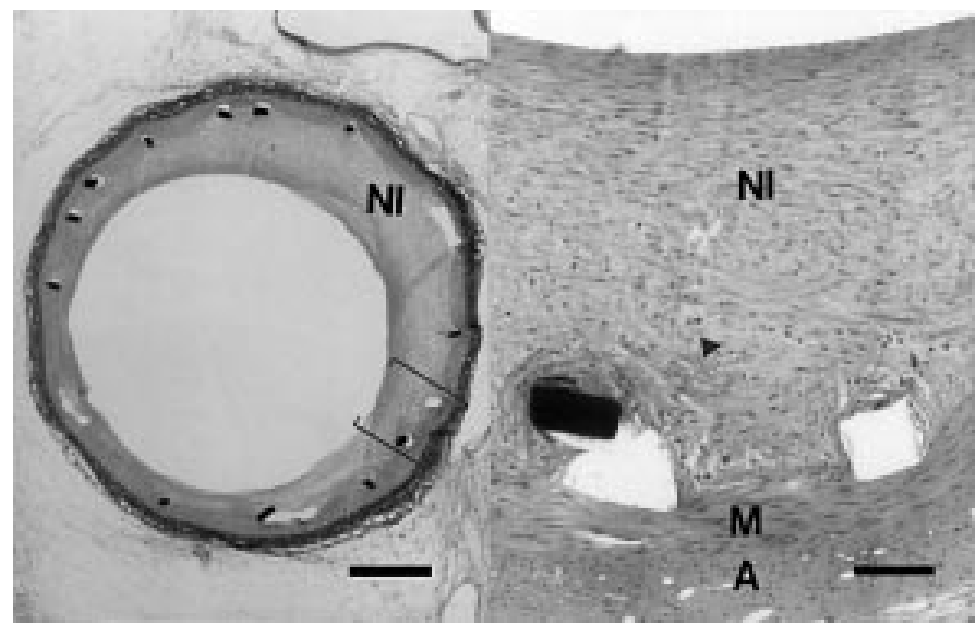

Figure 4 Overview (left) of a stented artery at four weeks showing an asymmetric neointima (bar $=500 \mu \mathrm{m}$ ), with detail (right) showing cells in a haphazard orientation with thrombus remnants (arrowhead) in the intimal/medial border zone (bar $=100 \mu \mathrm{m})$. NI, neointima; $M$, media; $A$, adventitia; haematoxylin and eosin.

SEM (fig 3B) and amounted to $91 \%$ (range $76-93 \%$ ) for the coated stent and $92 \%$ (range

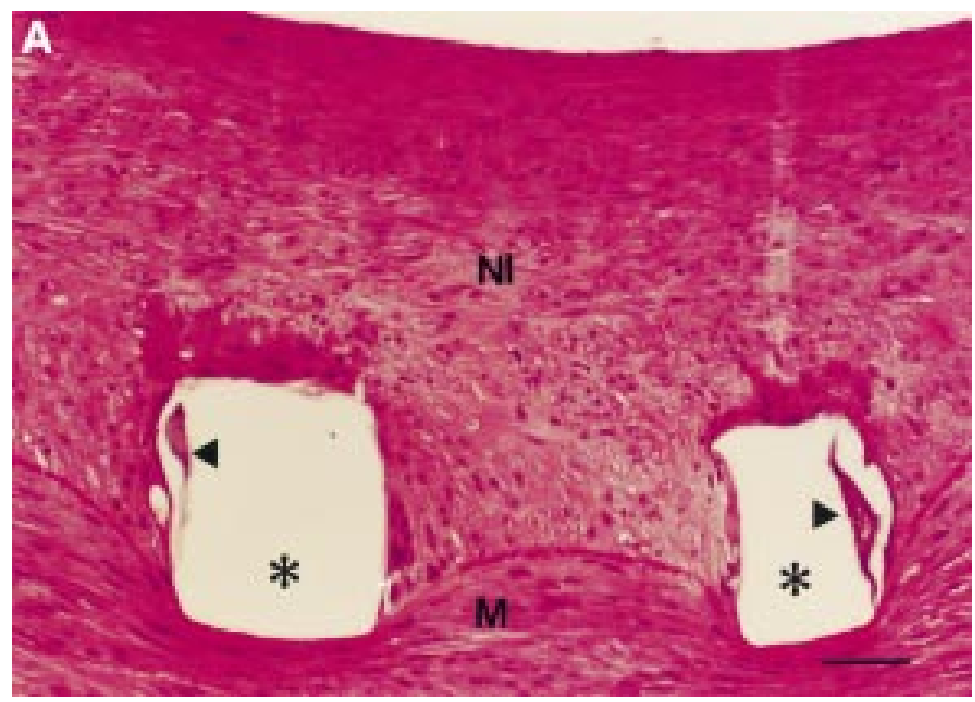

B

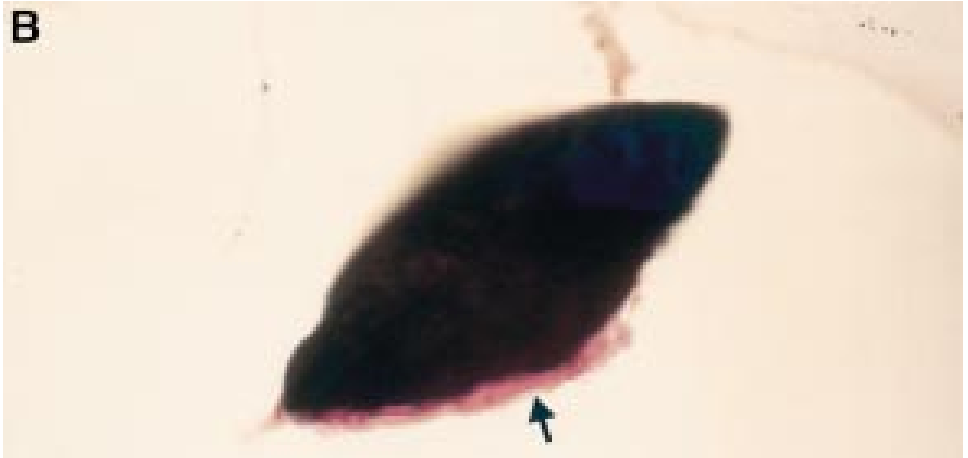

Figure 5 (A) Detail of purple stained coating (arrowheads) observed in the stent strut
void $\left({ }^{\star}\right) 12$ weeks after implantation of a phosphorylcholine coated stent (bar $=45 \mu \mathrm{m}$ ). NI, neointima; $M$, media; haematoxylin and eosin. (B) Detail of the cut surface of a stent strut from a non-implanted coated stent (bar $=20 \mu \mathrm{m})$. The phosphorylcholine coating (arrow) seen at the strut edge is similar in appearance to that seen in A. Haematoxylin and eosin.
$70-98 \%)$ for the non-coated stent, which was not significantly different.

\section{Neointimal formation}

The data for the four and 12 week study groups are summarised in table 5 . There is no significant difference in intimal thickness and area between the coated and non-coated stents at four weeks. While every attempt was made to implant the stents with minimal vascular damage (balloon:artery ratio of approximately 1), on three occasions stent implantation resulted in excessive vascular damage, with a concomitant inflammatory response in the 12 week group. Analysis of this group was therefore performed with (coated $\mathrm{n}=8$, non-coated $\mathrm{n}=8$ ) and without (coated $\mathrm{n}=6$, non-coated $\mathrm{n}=7$ ) inclusion of these vessels in an attempt to ascertain whether the inflammatory reaction somehow masked any small differences in intimal thickness or area in this group. The results in table 4 show that when the oversized vessels are excluded from analysis, there is no significant difference in the intimal thickness and area between the phosphorylcholine coated and non-coated groups at 12 weeks.

\section{Discussion}

Although coronary stenting is regarded as a major success in interventional cardiology, the problem of restenosis, and to a lesser extent that of stent thrombosis, remain limiting factors that restrict its use in a wider patient population.

Clinically approved stents are all made of metal. In an effort to reduce the above mentioned problems, coating the metal with a molecule that mimics a biological, naturally occurring molecule (a form of biological camouflage or biomimicry) has raised hopes that these problems can be reduced or eliminated. ${ }^{14} 15$ In this respect, our study addressed the effects of coating a stainless steel metal stent with a synthetic polymer containing a phosphorylcholine head group. Previous work has shown its success in improving biocompatibility of surgical equipment and guide wires ${ }^{4-7}$ and in reducing neointimal hyperplasia in synthetic vascular grafts in a canine model. ${ }^{16}$

OBJECTIVE AND MAIN FINDINGS

The main objective of this study was to determine the biocompatibility of the phosphorylcholine coating over a period of up to 12 weeks, comparing it to a non-coated equivalent. The main finding was that the coating has an excellent biocompatibility. The phosphorylcholine coating did not induce stent thrombosis, had no adverse effect on the rate of reendothelialisation, and was present for the duration of the study. The wound healing response for the coated and non-coated stents was similar at both four and 12 weeks.

ANIMAL MODEL AND INJURY

In the porcine model of oversized stent implantation, the degree of vascular injury that accompanies stent implantation induces a variable amount of inflammation and neointimal 
Table 5 Coated stents

\begin{tabular}{|c|c|c|c|c|c|c|c|}
\hline \multirow[b]{2}{*}{ Author } & \multirow[b]{2}{*}{ Stent } & \multirow[b]{2}{*}{ Animal model } & \multirow[b]{2}{*}{ Coating } & \multirow[b]{2}{*}{ Control } & \multicolumn{2}{|c|}{ Neointimal thickness } & \multirow{2}{*}{$\begin{array}{l}\text { Duration } \\
\text { (weeks) }\end{array}$} \\
\hline & & & & & Coated & Control & \\
\hline \multirow[t]{2}{*}{-} & \multirow[t]{2}{*}{$\operatorname{div} Y$ sio } & \multirow[t]{2}{*}{ Porcine coronary, matched } & \multirow[t]{2}{*}{ PC } & Bare stent & $0.14(0.09) \oint$ & $0.15(0.13) \oint$ & 4 \\
\hline & & & & Bare stent & $0.10(0.08) \S$ & $0.09(0.07) \int$ & 12 \\
\hline \multirow[t]{2}{*}{ Kuiper $^{21}$} & \multirow[t]{2}{*}{ Palmaz-Schatz } & \multirow[t]{2}{*}{ Rabbit iliac, porcine coronary, matched } & \multirow[t]{2}{*}{ PC } & \multirow{2}{*}{ Bare stent } & $0.20(0.05)$ & $0.23(0.11)$ & 4 \\
\hline & & & & & $0.44(0.27)$ & $0.47(0.38)$ & 4 \\
\hline van der & Wiktor & Porcine coronary, matched & PGLA & Bare stent & $0.46(0.18)$ & $0.08(0.03)$ & 4 \\
\hline Giessen $^{9}$ & & & PEO & Bare stent & $2.36(0.60)$ & $0.38(0.17)$ & 4 \\
\hline \multirow[t]{2}{*}{ Hardhammer $^{17}$} & \multirow[t]{2}{*}{ Palmaz-Schatz } & \multirow[t]{2}{*}{ Porcine coronary, matched } & \multirow[t]{2}{*}{ Heparin } & Bare stent & $0.26(0.10)$ & $0.11(0.04)$ & 4 \\
\hline & & & & Bare stent & $0.15(0.06)$ & $0.20(0.05)$ & 12 \\
\hline $\begin{array}{l}\text { van der } \\
\quad \text { Giessen }{ }^{26}\end{array}$ & Wallstent & Porcine coronary, matched & Biogold & Bare stent & $\begin{array}{l}0.11 \\
(0.04-0.17)+\end{array}$ & $\begin{array}{l}0.10 \\
(0.07-0.19)+\end{array}$ & 12 \\
\hline de Scheerder ${ }^{27}$ & Not described & Porcine coronary, oversized injury model & $\mathrm{POP} / \mathrm{MPD}$ & POP stent & $0.99(0.28)$ & $1.74(0.84)$ & 6 \\
\hline $\operatorname{Cox}^{28}$ & Cook & Porcine coronary, oversized injury model & $\mathrm{CEL} / \mathrm{HEP} / \mathrm{MET}$ & Bare stent & - & - & 4 \\
\hline Lincoff $^{23}$ & Wiktor & Porcine coronary, oversized injury model & HMWPLLA/DEX & $\begin{array}{l}\text { PLLA stent } \\
\text { Bare stent }\end{array}$ & $0.79(0.44) \ddagger$ & $\begin{array}{l}0.81(0.23) \ddagger \\
0.88(0.31) \ddagger\end{array}$ & 4 \\
\hline Aggarwal $^{34}$ & Cook & Rabbit iliac, balloon injury model & CEL/GPIIb/IIIa & $\begin{array}{l}\mathrm{CEL} \pm \text { anti } \\
\mathrm{CMV}\end{array}$ & $0.12(0.04)$ & $0.11(0.07)$ & 4 \\
\hline
\end{tabular}

PC, phosphorylcholine; PGLA, polyglycolic/lactic acid; PEO, polyethyleneoxide; POP/MPD, polyorganophosphazene/methylpredisnolone; CEL/HEP/MET, cellulose/heparin/methotrexate; HMWPLLA/DEX, high molecular weight poly-L lactic acid/dexamethasone; CMV, cytomegalovirus.

$\star$ Representative values for the best and worst performing polymers are given; trange; $\neq$ values calculated from fig 6 in Lincoff $e t a l^{2}$; $\$$ for comparative purposes, the thickness of the wire struts have been deducted from the data.

growth. In this respect, variation in vessel wall response caused by the effect of coatings and the induced vessel injury are less easily distinguished from one another. In our study, therefore, we chose a matched size model for stent implantation, which allowed us to detect small differences in the vessel wall response to the phosphorylcholine coating without being overshadowed by a considerable response to injury. In the 12 week group, however, three stents were clearly oversized (two coated, one non-coated). Inclusion of the morphometric data for these animals would appear to suggest that the neointima increased in the coated group between four and 12 weeks. If the data are excluded for those animals in which oversized stents were implanted, however, then there is normal regression of the neointima in both groups at 12 weeks.

\section{BLOOD BIOCOMPATIBILITY AND EARLY WOUND} HEALING

In a previous study using the stainless steel Palmaz-Schatz stent (same material, different geometry and surface characteristics), stents thrombosed irrespective of whether aspirin was administered postoperatively. ${ }^{17}{ }^{18}$ Absence of thrombosis in our study in both the coated and non-coated groups may be explained by the fact that the geometry and/or surface characteristics of the stent are such that it is inherently less thrombogenic. In our animal model both the stent and the phosphorylcholine coating showed excellent blood compatibility.

Following stent implantation, it is desirable that the vascular wall heals as quickly as possible, thereby incorporating the stent into the vessel wall. Histological parameters of completed vessel wall healing are reendothelialisation and the progression of granulation tissue to a mature neointima. In a previous study, data suggested that a heparin coating delayed re-endothelialisation at four weeks, such that the neointimal thickening was also affected. ${ }^{17}$ We therefore used the rate of endothelialisation as a parameter of the early wound healing process. The effect of the phosphorylcholine coating on wound healing and neointimal formation after stenting is unknown. Theoretically the phosphorylcholine group might be expected to retard the rate of re-endothelialisation since it inhibits the deposition of plasma proteins onto the stent surface. ${ }^{19}$ The absence of a protein layer may make the stent surface less "attractive" for the endothelial cells to grow on. ${ }^{20}$ In this model, however, the percentage endothelial covering after five days as assessed by planimetry was similar in both the coated and non-coated groups $(91 \% v 92 \%)$. Therefore the phosphorylcholine coating did not delay the early wound healing response.

\section{TISSUE BIOCOMPATIBILITY}

At four weeks there was no difference in neointimal thickness between the coated and non-coated groups (coated $0.14(0.09) \mathrm{mm}$; non-coated $0.15(0.13) \mathrm{mm})$. These results correlate with those from Kuiper and colleagues in so far that they also found no difference in neointimal thickness between the coated and non-coated stents. ${ }^{21}$ That study restricted its follow up to 28 days only, however. In studying the biocompatibility of synthetic polymers it is important to study the reaction at multiple time points, given the potential for synthetic polymers to show delayed inflammatory reactions. We therefore studied the vessel wall reaction to the coating at multiple time points up to 12 weeks.

At 12 weeks in both the phosphorylcholine coated and non-coated groups, a morphologically mature neointima was formed. In the area of the stent strut voids macrophage giant cells were occasionally associated with the implant. Such cells were observed in both coated and non-coated groups, and are part of the normal reaction to foreign implants. In the phosphorylcholine group, evidence of the coating was observed in the stent strut voids up to three months postimplant. Given that such purple stained material is similar to that observed when stained cross sections of a non-implanted phosphorylcholine coated stent were examined for the presence of the coating (fig 5B), we conclude that this coating remains present up 
to three months postimplantation. Indeed, our findings have recently been corroborated by Tolhurst who reported results showing that the coating does not degrade and is stable up to six months postimplantation. ${ }^{22}$ (Although the phosphorylcholine coating on the stent is thin, some swelling of the polymer occurs during histological processing, such that it is visible with light microscopy.) The fact that there was a minimal inflammatory response to the coating is a reassuring finding, since the phosphorylcholine coating is composed of synthetic polymers and to date most synthetic materials used to coat stents have often been associated with intense inflammatory reactions and variable neointimal growth. ${ }^{93-25}$

\section{PHOSPHORYLCHOLINE COMPARED TO OTHER} COATINGS

Table 5 compares the neointimal thickness from our study with those of other studies using coated stents in both matched sized models and oversized injury models.

In matched sized models of stent implantation, ${ }^{9}{ }^{1726}$ when results of neointimal thickness for the control stents are grouped, the range of neointimal thickness is 0.10 $0.40 \mathrm{~mm}$. The thickness of the coated group is well within this range. Indeed the neointimal thickness of the phosphorylcholine coated group is comparable to that of the heparin coated Palmaz-Schatz stent, which was expected to be approved by the US Food and Drug Administration in 1999. Given that the phosphorylcholine coating can be regarded as a synthetic polymer, the results appear to be considerably better than those using PGLA and PEO strips (among others) applied to the Wiktor stent. ${ }^{9}$

In the 12 week phosphorylcholine coated group, two stents were oversized at implantation. If the mean neointimal thickness for these vessels $(0.62(0.11) \mathrm{mm})$ is compared to the grouped range in the oversized injury group $(0.11-1.74 \mathrm{~mm}),{ }^{23} 2728$ then the phosphorylcholine result (oversized group) again falls within this range. In the study of de Scheerder, the neointimal thickness of the eluting stent is reduced compared to the control POP stent $(0.99(0.28) \mathrm{mm} v 1.74(0.84) \mathrm{mm})^{27}$; this thickness, however, is still almost twice that of the neointimal thickness for the oversized coated stents in our study $(0.62(0.11) \mathrm{mm} v$ $0.99(0.28) \mathrm{mm})$. Therefore, in comparison to other studies of coated stents and irrespective of the model used, the synthetic phosphorylcholine coating performs well.

\section{POTENTIAL OF THE COATING}

The complex processes that lead to restenosis can probably never be resolved by a single treatment alone. The possibility of using a coated stent as a carrier of drugs has therefore great therapeutic potential. To date studies involving synthetic polymer coated stents can be divided into those used: (a) to explore the potential of various materials as polymer stent coatings $^{92-31}$; (b) for in vitro drug release kinetic studies ${ }^{32}{ }^{33}$; and (c) for in vivo efficiency studies of local drug delivery to the vessel wall..$^{23} 34$ The results of such experiments have generally shown that while drug release is feasible, the drug may be effective in reducing only the unwanted side effects of the polymer used, but not in reducing neointimal hyperplasia per se. In the present study the coating remained present up to 12 weeks postimplant, without excessive neointimal growth (compared to the control). While the amount of polymer remaining cannot be quantified in this study, and it cannot be ascertained if there is a gradient of polymer depletion over time, the long term therapeutic potential of this particular coating in its present form is significantly improved over currently available synthetic polymer stent coatings. Such findings suggest that this polymer can potentially be used as a vehicle for local drug delivery, and initial drug release studies are underway using this phosphorylcholine coated stent. By controlling the physiochemical properties of the coating (cross linked density, water content, isoelectric point, molecular weight between cross links) the stent coating can be tailored to the specific drugs under investigation.

\section{CONCLUSION}

Both phosphorylcholine coated and noncoated stents were implanted with a $100 \%$ success rate without incidence of acute stent thrombosis, despite an antiplatelet regimen of only aspirin. Phosphorylcholine applied to the stent as a coating does not interfere with endothelialisation as measured at five days after implantation. During the subsequent process of wound healing, the coated and non-coated stents elicit a tissue response that is similar in nature. The only observed difference between the two stents is the presence of the phosphorylcholine coating in the stent strut voids up to 12 weeks after implantation. Given the long term presence of a coating that shows no adverse inflammatory reaction, the phosphorylcholine coating shows potential as a suitable candidate for local drug delivery.

Mr Rob van Bremen is acknowledged for expert technical assistance. Biocompatibles Cardiovascular, UK are thanked for generously supplying the coated and non-coated stents used in
this study. This study was supported in part by a grant from the this study. This study was supported in part by a grant from the
Interuniversity Cardiology Institute of the Netherlands, project 18 and grant 95-117 of the Netherlands Heart Foundation.

1 Moussa I, Di Mario C, Di Francesco L, et al. Subacute stent thrombosis and the anticoagulation controversy: changes in
drug therapy, operator technique, and the impact of intravascular ultrasound. Am 7 Cardiol 1996;78(suppl 3A):1317 .

2 Keane D, Haase J, Slager CJ, et al. Comparative validation of quantitative coronary angiography systems. Results and mplications from a multicenter study using a standardised approach. Circulation 1995;91:2174-83.

3 Goods CM, Al-Shaibi KF, Yadav SS, et al. Utilisation of the coronary balloon-expandable coil stent without anticoagulation or intravascular ultrasound. Circulation 1996;93: 1803-8.

4 von Segesser LK, Olah A, Leskosek B, et al. Coagulation patterns in bovine left heart bypass with phospholipid versus heparin surface coating. ASAIO f 1993;39:43-6.

5 Hunter S, Angelini GD. Phosphatidylcholine-coated chest tubes improve drainage after open heart operation. Ann Thorac Surg 1993;56:1339-42.

6 Veil KR, Chronos NAF, Palmer SJ, et al. Phosphorylcholine: a biocompatible coating for coronary angioplasty devices [abstract]. Circulation 1995;92:2337.

7 Plante S, Juneau C. Thrombogenicity of PTCA guide wires: a scanning electron microscopy study [abstract]. Circulation 1997;96:4243.

8 Campbell EJ, O’Byrne V, Stratford PW, et al. Biocompatible surfaces using methacryloylphosphorylcholine laurylmethacrylate copolymer. ASAIO f 1994;40:M853-7. 
9 van der Giessen WJ, Lincoff AM, Schwartz RS, et al. Marked inflammatory sequelae to implantation of biode-
gradable and nonbiodegradable polymers in porcine gradable and nonbiodegradable polymers

10 van der Giessen WJ, Serruys PW, van Beusekom HM, et al. Coronary stenting with a new, radiopaque, balloonexpandable endoprosthesis in pigs. Circulation 1991;83: 1788-98.

11 Reiber JH, Serruys PW, Kooijman CJ, et al. Assessment of short-, medium-, and long-term variations in arterial dimensions from computer-assisted quantitation of coronary cineangiograms. Circulation 1985;71:280-8.

12 van Beusekom HMM, Whelan DM, Van der Plas M, et al. A practical and rapid method of histological processing for examination of coronary arteries containing metallic stents. Cardiovascular Pathology 1996;5:69-76.

13 van Beusekom HMM, van der Giessen WJ, Wagenvoort CA, et al. Histological features of a polymer endovascular prosthesis after transcatheter implantation in porcine arterprosthesis after transcatheter implantation in

14 Baron JH, de Bono DP, Azrin MA, et al. Adsorption and elution of c7E3Fab from polymer-coated stents in vitro: local delivery of an anti-thrombotic agent that also may inhibit restenosis [abstract]. Circulation 1997;96 2254.

15 McKenna CJ, Camrud AR, Wolff R, et al. Fibrin-film stenting in a porcine coronary injury model: efficacy and safety compared to uncoated stents [abstract]. Circulation 1997; 96:81.

16 Chen C, Lumsden AB, Ofenloch JC, et al. Phosphorylcholine coating of ePTFE grafts reduces neointimal hyperplasia in canine model. Ann Vasc Surg 1997;11:74-9.

17 Hardhammar PA, van Beusekom HMM, Emanuelsson HU, et al. Reduction in thrombotic events with heparin-coated Palmaz-Schatz stents in normal porcine coronary arteries. Circulation 1996;93:423-30.

18 Rogers C, Edelman ER. Endovascular stent design dictates experimental restenosis and thrombosis. Circulation 1995; 91:2995-3001.

19 Ikada Y. Surface modification of polymers for medical applications. Biomaterials 1994;15:725-36.

20 van Wachem PB, Vreriks CM, Beugeling T, et al. The influence of protein adsorption on interactions of cultured human endothelial cells with polymers. 7 Biomed Mater Res 1987;21:701-18.

21 Kuiper KKJ, Robinson KA, Chronos NAF, et al. Phosphorylcholine-coated metallic stents in rabbit iliac and porcine coronary arteries. Scand Cardiovasc 7 1998;32: 261-8.

22 Tolhurst LA. The analysis of post implant biodivYsio stents. Proceedings of the Medical Device Technology Conference,
March 1999, London, UK. Chester, UK: Advanstar Communications, 1999:427-41.

23 Lincoff AM, Furst JG, Ellis SG, et al. Sustained local delivery of dexamethasone by a novel intravascular eluting stent to prevent restenosis in the porcine coronary injury model. f Am Coll Cardiol 1997;29:808-16.

24 Wilczek K, Scheerder ID, Wang K, et al. Comparison of self-expanding polyethylene terephthalate and metallic stents implanted in porcine iliac arteries. Cardiovasc stents implanted in porcine 1
Intervent Radiol 1996;19:176-80.

25 Murphy JG, Schwartz RS, Edwards WD, et al. Percutaneous polymeric stents in porcine coronary arteries. Initial experience with polyethylene terephthalate stents. Circulation 1992;86:1596-604.

26 van der Giessen WJ, van Beusekom HMM, van Houten CD, t al. Coronary stenting with polymer-coated and uncoated self-expanding endoprostheses in pigs. Coronary Artery Disease 1992;3:631-40.

27 de Scheerder I, Wang K, Wilczek K, et al. Local methylprednisolone inhibition of foreign body response to coated intracoronary stents. Coronary Artery Disease 1996;7:161-6.

28 Cox DA, Anderson PG, Roubin GS, et al. Effect of local delivery of heparin and methotrexate on neointimal proliferation in stented porcine coronary arteries. Coronary Artery Disease 1992;3:238-48.

29 De Scheerder IK, Wilczek KL, Verbeken EV, et al. Biocompatibility of polymer-coated oversized metallic stents implanted in normal porcine coronary arteries. Atherosclerosis 1995;114:105-14.

30 De Scheerder IK, Wilczek KL, Verbeken EV, et al. Biocompatibility of biodegradable and nonbiodegradable polymercoated stents implanted in porcine peripheral arteries. Cardiovasc Intervent Radiol 1995;18:227-32.

31 Fontaine AB, Koelling K, Passos SD, et al. Polymeric surface modifications of tantalum stents. $\mathcal{F}$ Endovasc Surg 1996;3:276-83.

32 Dev V, Eigler N, Sheth S, et al. Kinetics of drug delivery to the arterial wall via polyurethane-coated removable nitinol stent: comparative study of two drugs. Cathet Cardiovasc Diagn 1995;34:272-8.

33 Lambert TL, Dev V, Rechavia E, et al. Localised arterial wall drug delivery from a polymer-coated removable metallic stent. Kinetics, distribution, and bioactivity of forskolin. Circulation 1994;90:1003-11.

34 Aggarwal RK, Ireland DC, Azrin MA, et al. Antithrombotic potential of polymer-coated stents eluting platelet glycoprotein IIb/IIIa receptor antibody. Circulation 1996;94: 3311-17. 